\title{
Atrial (? Sinus) Tachycardia With Block (Well Concealed)
}

David H. Spodick, MD, DSC

click an author to search for more articles by that author

A 57-year-old woman with coronary heart disease came to the emergency department because of general malaise. Best seen only in leads II, III, and aVF are apparently ectopic (possibly sinus) $\mathrm{P}$ waves ( $\mathrm{P}^{-}$) at approximately 180/min, mostly in a fixed 2:1 ratio to the QRS (Mobitz II AV block). The first three beats, however, may represent Wenckebach (Mobitz I) block with increasing PR on beats 1 and 2 and complete block of the subsequent $P\left(P^{-}\right)$wave; this is repeated in beats 8,9 , and 10 . The $P$, as seen in lead $V_{1}(P)$, is wide, consistent with interatrial block, but this cannot be interpreted during an ectopic atrial rhythm. Atrial tachycardia with block is usually a toxic rhythm, frequently due to digitalis excess.

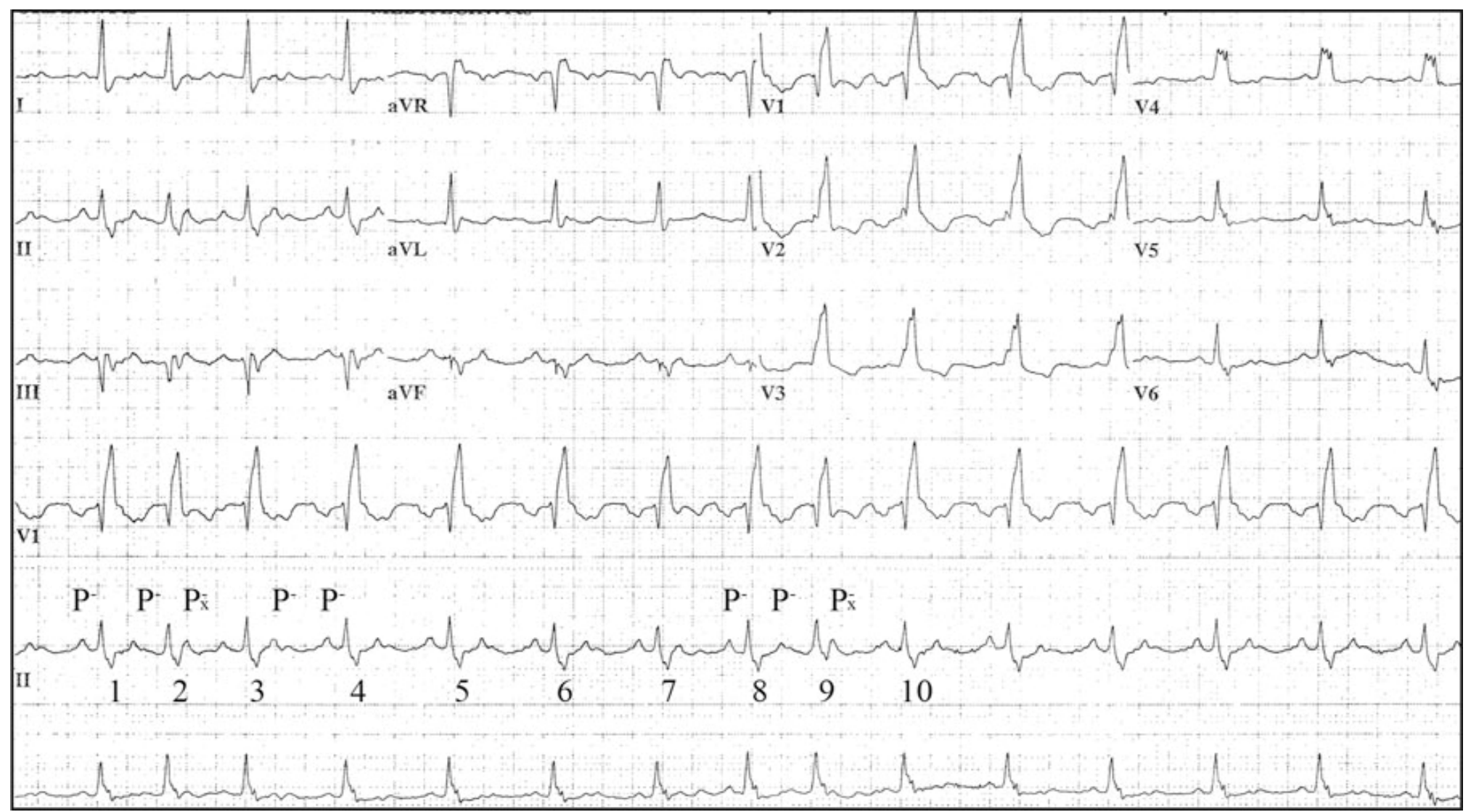

